\title{
Online Performance Tracking
}

\section{Ardil}

Okan University, Istanbul, Turkey

\section{S. Bilgen}

Okan University, Istanbul, Turkey

\begin{abstract}
This paper describes the conceptual framework, development process, and theoretical structure for an online performance tracking system. The principle factors influencing online performance tracking are described using the weighted sum model as computational method on measures of performance. Input data for the computational model were obtained directly from a real-time system in an actual organization that directly measured staff performance. In this multicriteria decision-making approach, the criteria weights are computed using the entropy information method and ranking of 15 alternatives (employees) is computed using the weighted sum model. Computational results obtained using the online performance appraisal system are evaluated and discussed relative to the weighted sum model.
\end{abstract}

Keywords: performance appraisal, performance evaluation, weighted sum model, entropy information method, online performance tracking, multicriteria decision making, multicriteria analysis, reference objective theory.

\section{JEL Classification: C53.}

(C) The Authors, 2017. This article is published with open access at ARMG Publishing.

\section{Introduction}

Objective method-based evaluation of online staff performance using multicriteria decision-making approach is of major impact on the business's superiority to its competitors in the global competitive environment. Online performance tracking is the conception and designing of performance appraisal based on online collection and evaluation of performance indicators for work being done. Performance is a concept that defines the extent to which an individual can use his or her potential or real knowledge, skills and abilities to reach targets or expectations, which are often quantified as the percentage of human capacity to successfully complete a scheduled job.

Performance evaluation is defined as the periodic and systematic evaluation of the ability of the employee to achieve success and development. Performance appraisal of employees in relation to a particular position is a key task towards managing the human resources of an organization. Performance appraisal refers to the methods and processes used by organizations to assess the level of performance of their employees. This process usually includes measuring employees' performance and providing them with feedback regarding the level and quality of their performance. The main goal of the performance appraisal in organizations is to improve employee performance $[1,2]$. Supervisors in organizations are concerned with performance appraisal judgments and evaluations that they have to make on their subordinates. Online performance assessment mainly provides support for the human resource management for decision making process in the workforce selection, placement, planning and budgeting of the employees. Therefore, discovering and promoting the most qualified employees is essential because valuable human expertise is the main source of competitive advantages for the organizations. Thus, qualification, subject knowledge, communication skills, past experience, negative activity, leadership, managing power, and mental stress are the most important requirements towards performance analyzing of employees.

In this study we focus on multicriteria decision making which provides a proper quantitative computational model to evaluate employee performance in the information technology sector. The determination of the performance of staff doing online work, based on objective and quantitative methods gives regular, continuous and periodic evaluation results to human resources management. The fact that human resources data in enterprises is up-to-date, reliable and electronic is very important for users and decision-makers. 
The correct selection and placement of employees according to the results of online performance evaluations in the enterprises directly contribute to the productivity, efficiency, and the effectiveness of the enterprise. Online businesses are using the evolving information technology infrastructure to evaluate online employee performance and perform organizational performance evaluation activities. These online businesses are significantly able to provide better quality and efficient marketing, production, financing, accounting, research and development, public relations, human resources and management functions. In this study, six significant evaluating criteria were taken into consideration in online tracking and evaluation of the employee's performance. A multiobjective decision making problem can be represented as in Figure 1.

\begin{tabular}{|l|c|c|c|c|c|c|}
\hline & $C_{1}$ & $C_{2}$ & $C_{3}$ &. &. & $C_{m}$ \\
\hline$S_{1}$ & $x_{11}$ & $x_{12}$ & $x_{13}$ &. &. & $x_{1 m}$ \\
\hline$S_{2}$ & $x_{21}$ & $x_{22}$ & $x_{23}$ &. &. & $x_{2 m}$ \\
\hline$S_{3}$ & $x_{31}$ & $x_{32}$ & $x_{33}$ &. &. & $x_{3 m}$ \\
\hline$\cdot$ &. &. &. &. &. &. \\
\hline$\cdot$ & $\cdot$ &. &. &. &. &. \\
\hline$S_{n}$ & $x_{n 1}$ & $x_{n 2}$ & $x_{n 3}$ &. &. & $x_{n m}$ \\
\hline & $\omega_{1}$ & $\omega_{2}$ & $\omega_{3}$ &. &. & $\omega_{m}$ \\
\hline
\end{tabular}

Figure 1. Representation of a multiobjective decision making problem

In this representation, $S_{1}, S_{2}, \ldots, S_{n}$ are possible alternatives among which decision makers have to choose, $C_{1}, C_{2}, \ldots, C_{m}$ are alternative criteria for performance measurement, $x_{i j}$ is the rating of alternative $S_{i}$ with respect to criterion $C_{j}, \omega_{j}$ is the weight of criterion $C_{j}[3-5]$.

Multicriteria decision making (MCDM) is often associated with the selection of one out of a set of alternatives. The impact of multiple, often conflicting, criteria is also taken into account during the evaluation of alternatives. In ordinary multicriteria decision making methods, the ratings and the weights of the criteria are known precisely, whereas in an imprecise and uncertain environment, it is an unrealistic assumption that the knowledge and representation of a decision maker are so precise.

These methods have mainly been based on the use of crisp numbers, and they are called ordinary MCDM methods. However, in the real world, many decision making problems take place in the environment that is characterized by the absence of precise and reliable information, or they are associated with some kind of predictions, uncertainties and ambiguities. Therefore, ordinary MCDM methods have not provided the adequate ability to solve such kinds of problems.

Human judgment including preferences is often vague and decision maker cannot estimate a preference with exact numerical values. In these situations, determining the exact value of the attributes is difficult or impossible. A significant progress in solving real world decision making problems appeared after Zadeh [6] introduced the Fuzzy sets theory. As part of the fuzzy set theory, fuzzy numbers are introduced, usually based on triangular or trapezoidal shapes, which are much more suitable for modeling and solving a number of complex decision making problems.

The fuzzy multiple criteria decision making methodology, which was subsequently widely accepted and used for solving many decision making problems, was introduced based on fuzzy sets theory. Therefore, fuzzy and stochastic decision making approaches are frequently used to describe and treat imprecise and uncertain elements present in a MCDM [7-9]. The fuzzy parameters are assumed to be with known membership functions, and in stochastic decision making [10-13], parameters are assumed to have known probability distributions. However, in reality, to a decision maker it is not always easy to specify the membership function or probability distribution in an inexact environment. However, MCDM methods use different aggregation functions and different normalization methods [14-19]. In this paper, entropy method is used to compute the weights of the criteria to be used in evaluating the performances of the alternatives (employees).

The concept of Pareto optimization [20] has been proposed for such problems of selecting dominant ones among a set of alternative optimization objectives. 
Pareto-Set is introduced in section 2, MCDM is presented in section 3. In section 4, entropy method is presented to compute the criteria weights. In section 5, weighted sum method (WSM) is employed for performance ranking on the basis of objective criteria weights. Reference objectives in multiobjective optimization approach is considered for multicriteria analysis. In section 6 , an illustrative application is presented to show an application of entropy based WSM method. Finally, the paper is concluded in section 7.

\section{Pareto-set}

The Pareto set is a set of dominant alternatives, which does not include dominated alternatives. An alternative ' $\mathrm{A}$ ' is dominating an alternative ' $\mathrm{B}$ ' if at least one objective of ' $\mathrm{A}$ ' is better than the objective in ' $\mathrm{B}$ ' and all other objectives in ' $\mathrm{A}$ ' are at least equal to the objectives in 'B'. These dominating alternatives are called Pareto optimal [20].

It has been shown [21] that independent of the possible weights and the number of objectives, it is possible to pick an alternative within the Pareto set.

It is assumed that the chosen algorithm (1) picks an alternative $S_{i}^{\text {optimum }}$ which is not an element of the Pareto set. Compliant with such an algorithm, it can be determined that

$$
S_{i}^{*}=\sum_{j=1}^{n} \omega_{j} x_{i j}=\max _{i} \sum_{j=1}^{n} \omega_{j} x_{i j}
$$

Since $S_{i}^{\text {optimum }}$ is not an element of the Pareto set, an alternative $S_{i}^{\text {pareto }}$ has to exist which dominates $S_{i}^{\text {optimum }}$. According to the definition of the Pareto set, this alternative has one higher value for at least one criterion than $S_{i}^{\text {optimum }}$ without having a lower value for all other objectives. This is in contradiction to

$S_{i}^{*}=\max _{i} \sum_{j=1}^{n} \omega_{j} x_{i j}$

since the score is better for $S_{i}^{\text {pareto }}$ with unchanged weights [22]. The decision making paradox relates to decision making and the quest for determining reliable decision making methods. It is a fundamental paradox in multicriteria decision analysis (MCDA) / multi-criteria decision making (MCDM), and decision analysis problems. Some multicriteria decision-making methods have been quested to exhibit the decision-making paradox are the weighted sum model (WSM), the analytic hierarchy process (AHP), the weighted product model (WPM), the ELECTRE method, and the TOPSIS method [5, 23].

\section{Multicriteria decision making}

Decision making is to reach the set goal and to choose the best alternative from alternatives on the way forward for this goal. Multicriteria decision making is the solution of the problems that multiple and selfconflicting goals want to be real. Multiplecriteria decision making (MCDM) is considered as a complex decision making model involving both quantitative and qualitative factors. Some MCDM techniques and approaches have been suggested to choosing the optimal probable options. Multicriteria decision analysis methods are classified into multiobjective decision making (MODM) and multiattribute decision making (MADM) as shown in Table 1.

The main distinction between the two groups of methods is based on the number of alternatives under evaluation. The MADM methods are designed for selecting discrete alternatives while MODM are more adequate to deal with multiobjective planning problems, when a theoretically infinite number of continuous alternatives are defined by a set of constraints on a vector of decision variables [24].

Multiobjective decision making has the ability to solve more than one criteria and option at the same time. In the emergence of the concept of multiobjective decision making, the objective problem plays an important role in choosing the right choice to reach important decisions in the complex situations.

Multiattribute decision making takes into account the multiple criteria, objectives and characteristics that are not identical to each other, to choose the best alternative among the available alternatives, actions and options.

Multicriteria decision making method considers more than one alternative based on more than one criterion is to be sorted according to considered criteria, and to select these criteria. 
Multicriteria optimization is the process of determining the best feasible solution according to the established criteria representing different effects of the decision making problem. The weighted sum model (WSM) based entropy method is proposed for evaluating the results of the online performance tracking decision making problem and selecting the personnel.

Table 1. Comparison of MODM and MADM methods [25]

\begin{tabular}{|l|l|l|}
\hline \multicolumn{1}{|c|}{ Criteria for comparison } & \multicolumn{1}{c|}{ MODM } & MADM \\
\hline Criteria defined by & Objectives & Attributes \\
\hline Objectives defined & Explicitly & Implicitly \\
\hline Attributes defined & Implicitly & Explicitly \\
\hline Constraints defined & Explicitly & Implicitly \\
\hline Alternatives defined & Implicitly & Explicitly \\
\hline Number of alternatives & Infinite (large) & Finite (small) \\
\hline Decision maker's control & Significant & Limited \\
\hline Decision modelling paradigm & Process-oriented & Outcome-oriented \\
\hline Relevant to & Design/search & Evaluation/choice \\
\hline
\end{tabular}

Multicriteria decision making problems can be examined under three main headings. These multiobjective optimization problems are classified as selection, classification and ranking.

Selection problems: The purpose of the selection problem is to determine the best of the alternatives or to make a good selection from a set of many alternatives that are difficult or comparable to each other. The right alternative is to be chosen from the alternative set.

Classification problems: In such problems, alternatives are classified according to certain criteria or preferences. The aim here is to bring together alternatives that show similar characteristics and behaviors in the alternative set.

Ranking problems: Alternatives considered in multicriteria optimization ranking problems can be measured/ identified from good to bad in the alternative set.

Multicriteria decision making in performance evaluation process is described in 10 distinct steps as shown in Table 2.

Table 2. Multicriteria decision making in performance evaluation process

\begin{tabular}{|c|l|}
\hline 1 & Identification of problem \\
\hline 2 & Determination of performance evaluation and selection criteria \\
\hline 3 & Determination of decision alternatives \\
\hline 4 & Determination of performance standards \\
\hline 5 & Determination of the hierarchical structure of the decision problem \\
\hline 6 & Determination of method \\
\hline 7 & Measurement of Actual Performance \\
\hline 8 & Comparing actual performance to standards \\
\hline 9 & Evaluation of results \\
\hline 10 & Identifying the best alternative \\
\hline
\end{tabular}

\section{Determination of the entropy matrix}

This paper presents an integration of entropy-based weights and multicriteria optimization method within multicriteria decision analysis (MCDA). Entropy is a thermodynamic quantity representing the unavailability of a system's thermal energy for conversion into mechanical work, often interpreted as the degree of disorder or randomness in the system. The second law of thermodynamics states that there is a natural tendency of any isolated system to degenerate into a more disordered state. Entropy always increases with time in thermodynamical systems.

Information entropy is the average amount of information produced by a probabilistic stochastic source of data. It measures the amount of uncertainty of an unknown or random quantity. Information entropy is a measure of the unpredictable nature of a set of possible elements. Information entropy is a criterion for the 
amount of uncertainty represented by discrete probability distributions; and is used to measure the amount of useful information that data set provides. The uncertainty is higher in the data group with high entropy value.

Entropy approach [26] is the most frequently used method to determine the importance order of the criteria in the decision matrix which contains a certain amount of information for the alternatives. The method is based on the fact that the information on the significance of a criterion found in the decision matrix comes from the contradictions between the data sets [27].

The objective weights of the criteria are determined from the distinction and intensity of the contradictions from the outputs of the alternatives. The entropy method can be applied in cases where the data of the decision matrix is known to compute the objective weights. The smaller the entropy in value, the smaller the entropy weight, the smaller the differences of different alternatives in this particular criterion, and the less specific the criterion, the less critical this decision is in the decision-making process.

The entropy method is an objective evaluation method because it calculates the criteria weights considering only the data set without considering the subjective judgments of the decision makers in determining the significance levels of the criteria without forming a hierarchical structure of the decision problem. The entropy method is a suitable method for finding the appropriate weights of each criterion in multi-criteria decision making problems. Information entropy method is used for determination of evaluating indicators / weights for an MADM problem especially when obtaining a suitable weight based on the preferences and decision maker experiments are not possible. The original procedure of entropy method can be expressed in a series of steps:

S1: Normalize the decision matrix.

Set $p_{i j}=\frac{x_{i j}}{\sum_{j=1}^{m} x_{i j}} ; j=1, \ldots, m ; i=1, \ldots, n$

The raw performance data in the decision matrix are normalized to eliminate anomalies with different measurement units and scales. This process transforms different scales and units among various criteria into common measurable units to allow for comparisons of different criteria.

S2: Compute entropy $e_{j}$ as $e_{j}=-e_{0} \sum_{j=1}^{m} p_{i j} \cdot \ln p_{i j}, i=1, \ldots ., n$, where $e_{0}$ is the entropy constant and is equal to $(\ln m)^{-1}$, and $p_{i j} \cdot \ln p_{i j}$ is defined as 0 if $p_{i j}=0$, where, $e_{0}$ is constant such that $0 \leq e_{j} \leq 1$.

S3: Set $d_{j}=1-e_{j}, j=1, \ldots, n$ as the degree of divergence and $e_{j}$ is the information entropy of attribute $C_{j}$.

S4: Set $\omega_{j}=\frac{d_{j}}{\sum_{i=1}^{n} d_{i}}, j=1, \ldots, n$ as the degree of importance of attribute $\mathrm{j}$. Assume that $\omega_{j}$ be the weight of criteria $C_{j}$, where $\omega_{j}=\in[0,1], \sum_{j=1}^{n} \omega_{j}=1$.

\section{Weighted sum method (WSM)}

\section{A. Weighted sum method for multicriteria decision making}

In decision theory, the weighted sum model (WSM) [5,28] is the simplest multicriteria decision analysis (MCDA) / multicriteria decision making method (MCDM) for evaluating a number of alternatives in terms of a number of decision criteria. It is applicable only when all the data are expressed in exactly the same unit after the normalization of decision matrix. The WSM method is widely employed for multi objective optimization problems. It combines the different objectives and weights corresponding to those objectives to create a single score for each alternative to make them comparable in alternatives set.

$S_{i}^{W S M-\text { score }}=\sum_{j=1}^{n} \omega_{j} x_{i j}$ 
$S_{i}^{* W S M-s c o r e}=\sum_{j=1}^{n} \omega_{j} x_{i j}=\max _{i} \sum_{j=1}^{n} \omega_{j} x_{i j}$

where the WSM-score for an alternative $S_{i}$ denoted as $S_{i}^{W S M-s c o r e}$ is calculated by adding the products of a weight $\omega_{j}$ with its corresponding parameter $x_{i j}$, the value of this objective. The best alternative is chosen as the one which has the maximum WSM score $\left(S_{i}^{* \text { WSM-score }}\right)$. The different objectives are assumed to be positive (benefit): the higher the score, the better the alternative. For the maximization case, the best alternative is the one that yields the maximum total performance value. Assuming objectives to be negative (cost), the best alternative has equivalently the lowest score. For the minimization case, the best alternative is the one that yields the minimum total performance value.

\section{B. Steps of the weighted sum method for multiobjective optimization problem}

A multicriteria decision analysis (MCDA) model for online performance tracking is proposed to incorporate various objectives in decision making process, based on the weighted sum model, to achieve a suitable execution algorithm. The experimental performance studies show that comparing with models, the proposed model is able to achieve its goal while incurs almost no additional computational overhead. The MCDM problem using multicriteria optimization can be precisely expressed using the following steps:

S1: Determine the optimal performance rating for each criterion.

The decision maker sets the optimal performance rating for each criterion. If the decision maker does not have preferences, the optimal performance ratings are calculated as:

$x_{0 j}=\left\{\begin{array}{l}\max _{i} x_{i j} ; j \in \Omega_{\max } \\ \min _{i} x_{i j} ; j \in \Omega_{\min }\end{array}\right.$

where $x_{0 j}$ denotes the optimal performance rating of $j$. criterion, $\Omega_{\max }$ denotes the benefit criteria, and $\Omega_{\min }$ denotes the set of cost criteria.

S2: Compute the normalized decision matrix.

$r_{i j}=\left\{\begin{array}{l}\frac{x_{i j}}{\sum_{i=0}^{m} x_{i j}}, j \in \Omega_{\max } \\ \frac{1 / x_{i j}}{\sum_{i=0}^{m} 1 / x_{i j}}, j \in \Omega_{\min }\end{array}\right.$

where $r_{i j}$ denotes the normalized performance rating of $i^{t h}$ alternative in relation to the $j^{\text {th }}$ criterion, $i=0,1, \ldots, m$.

S3: Reference objectives in multiobjective optimization

In multiobjective optimization, decision maker's preferences is to assign targeted values (goals) to conflicting objectives as well as relative weights and priority levels for attaining the goals. The reference objective method in multiojective optmization is a generalization of the goal programming method [30] and of the method of displaced ideals developed by Zeleny [31]. A reference point or reference objective is a suggestion $r_{i}$ by the decision maker which reflects the desired level of the objective. The reference objectives in multiobjective optimization approach uses the normalized performance of $i^{\text {th }}$ alternative on $j^{\text {th }}$ criterion, which is computed by Eq. (6). A maximum criterion reference objective is determined among normalized performances and this reference objective is more realistic and non-subjective as the coordinates $r_{i}$. For determining $r_{i}$, the reference objective theory chooses for maximization a reference objective, $r_{i}$, which coordinates the highest coordinate per objective of all candidate alternatives. For minimization, the lowest coordinate is chosen for multiobjective optimization.

$r_{i}=\left\{\begin{array}{l}\max _{i} r_{i j} ; j \in \Omega_{\text {max }} \\ \min _{i} r_{i j} ; j \in \Omega_{\text {min }}\end{array}\right.$ 
The Chebyshev min-max metric [29] is chosen as the most appropriate for the reference objective approach in order to measure the distance between the alternatives and the reference objective. The reference objective approach is formulated as:

$$
z_{i}=\min _{j}\left\{\max _{i}\left|r_{i}-r_{i j}\right|\right\}
$$

where, $r_{i j}$ is the normalized performance of $i^{\text {th }}$ alternative on $j^{\text {th }}$ criterion. $i=1,2, \ldots, n$ are the objectives, $j=$ $1,2, \ldots, m$ are the alternatives. $r_{i}$ is the $j^{\text {th }}$ coordinate of the reference objective, i.e., the most desirable performances of all alternatives with respect to $j^{\text {th }}$ criterion. $r_{i}=$ the $i^{\text {th }}$ coordinate of the maximal criterion reference objective, each coordinate of the reference objective is selected as the highest corresponding coordinate of the alternatives, $r_{i j}$ is the normalized objective $i$ of alternative $j$. If the decision maker wants to give more importance to a criterion than the others, Eq. (8) is reformulated by considering weights of criteria as:

$$
z_{i}=\min _{j}\left\{\max _{i}\left|\omega_{j} r_{i}-\omega_{j} r_{i j}\right|\right\}
$$

Finally, the alternatives are ranked and the best alternative is chosen with the minimum total deviation from the reference objectives.

S4:Compute the weighted normalized decision matrix.

$$
u_{i j}=\omega_{j} r_{i j}
$$

where $u_{i j}$ denotes the weighted normalized performance rating of $i^{\text {th }}$ alternative in relation to the $j^{\text {th }}$ criterion, $i=0,1, \ldots, m$.

S5:Compute the overall performance rating for each alternative.

$$
S_{i}=\sum_{j=1}^{n} u_{i j}
$$

where $S_{i}$ denotes the overall performance rating of $i^{\text {th }}$ alternative, $i=0,1, \ldots, m$.

S6:Compute the degree of utility for each alternative.

The relative performances of considered alternatives is determined in relation to the optimal alternative using the degree of utility.

$$
Q_{i}=\frac{S_{i}}{S_{0}}
$$

where $Q_{i}$ denotes the degree of utility of $i^{\text {th }}$ alternative, and $S_{0}$ is the overall performance index of optimal alternative, $i=1, \ldots, m$.

S7:Rank alternatives and select the most acceptable alternative.

$$
S^{*}=\left\{S_{i} \mid \max _{i} Q_{i}\right\}
$$

where $S^{*}$ denotes the most acceptable alternative, $i=1, \ldots, m$.

\section{Application}

In this section, we consider a real case study to demonstrate the applicability of the entropy based weighted sum method (WSM) in solving multiobjective decision making problem. The case study is associated with an organization active in the information technology sector.

The organization delivers online information processing service with 15 university graduate employees, whose academic computing and english language competency qualifications and skills for work assignments, are considered to be proficient by standart ALES and UDS scores. The organization 
management is approached to evaluate the performance of employees for their administrative and organizational goals.

The human resources department of the organization is responsible from this task namely identifying the alternatives and selecting the best employee. There are three employees / decision makers who determine the criteria according to the needs of the organization in the human resources department. The criteria set, considered beneficial, for online performance tracking are, quantity of work, quaility of work, technical skills, cooperation, loyalty and willingness.

Necessary data are collected from the organization in information technology sector, whilst the 15 employees are systematically tracked online for 21 regular work days in July 2017 between 00:09 AM - 13:00 PM and 14:00 PM-18:00 PM. Table 3 shows the decision matrix of the problem with the online collected data (dimensionless performance data set scores) which summarizes the performance of each staff member with respect to each criterion.

The multicriteria optimization problem will broadly be treated using three distinct computational methods; namely, entropy information method, weighted sum method, and reference objective method.

Entropy information method is used to discretize the average amount of information produced by a probabilistic stochastic source of data. The weights of criteria for alternatives in online performance tracking problem are objectively determined using the original procedure of information entropy method in a series of steps.

Weighted sum method is widely expanded with the consideration of optimal values (objectives) for solving the computational multiobjective optimization problem.

The optimal objectives set for multiobjective optimization are used as the reference values for ranking the performance of alternatives. Online performance tracking optimization problem is solved using the weighted sum method for a case study with six criteria and 15 employees in the organization from information technology sector.

The reference objective method finds the values of design variables which minimize the maximum objective function value over a given range of a set of performance goals for multiobjective optimization.

\section{A. The application of the Entropy method}

Entropy information method for determination of objective criteria weights from online collected data is introduced and explained. Information entropy is an amount of information that may be gained by observation of a system and it measures variation or changes in a series of events. The weight factors of six criteria for online performance tracking are determined by the entropy method and the ranking of different alternatives is computed using the weighted sum method (WSM). Entropy method is an objective method which determines the weights of attributes/criteria using objective decision matrix information. The entropy based WSM method is chosen because it has some advantages over other multiobjective methods.

Table 3. Decision matrix of the online performance tracking problem

\begin{tabular}{|l|c|c|c|c|c|c|}
\hline $\begin{array}{c}\text { Performance } \\
\text { criteria }\end{array}$ & $\begin{array}{c}\text { Quantity of } \\
\text { work }\end{array}$ & Quality of work & Technical skills & Cooperation & Loyalty & Willingness \\
\hline $\begin{array}{c}\text { Optimization } \\
\text { direction }\end{array}$ & $\max$ & $\max$ & $\max$ & $\max$ & $\max$ & max \\
\hline & $\mathrm{C} 1$ & $\mathrm{C} 2$ & $\mathrm{C} 3$ & $\mathrm{C} 4$ & $\mathrm{C} 5$ & C6 \\
\hline S1 & 425 & 85 & 85 & 90 & 90 & 80 \\
\hline S2 & 410 & 80 & 85 & 80 & 80 & 75 \\
\hline S3 & 430 & 75 & 85 & 90 & 75 & 80 \\
\hline S4 & 375 & 90 & 75 & 95 & 80 & 95 \\
\hline S5 & 395 & 85 & 95 & 85 & 85 & 90 \\
\hline S6 & 415 & 90 & 95 & 90 & 85 & 85 \\
\hline S7 & 400 & 85 & 75 & 85 & 90 & 75 \\
\hline S8 & 440 & 90 & 90 & 75 & 85 & 85 \\
\hline S9 & & 85 & 95 & 75 & 85 & 100 \\
\hline
\end{tabular}


Table 3 (cont.). Decision matrix of the online performance tracking problem

\begin{tabular}{|l|c|c|c|c|c|c|}
\hline $\begin{array}{c}\text { Performance } \\
\text { criteria }\end{array}$ & $\begin{array}{c}\text { Quantity of } \\
\text { work }\end{array}$ & Quality of work & Technical skills & Cooperation & Loyalty & Willingness \\
\hline $\begin{array}{c}\text { Optimization } \\
\text { direction }\end{array}$ & $\max$ & $\max$ & $\max$ & $\max$ & $\max$ & $\max$ \\
\hline & $\mathrm{C} 1$ & $\mathrm{C} 2$ & $\mathrm{C} 3$ & $\mathrm{C} 4$ & $\mathrm{C} 5$ & C6 \\
\hline S10 & 460 & 85 & 85 & 95 & 80 & 85 \\
\hline S11 & 445 & 90 & 80 & 95 & 85 & 75 \\
\hline S12 & 390 & 75 & 100 & 80 & 90 & 80 \\
\hline S13 & 410 & 80 & 85 & 85 & 85 & 85 \\
\hline S14 & 430 & 75 & 90 & 85 & 95 & 90 \\
\hline S15 & 450 & 95 & 90 & 85 & 85 & 100 \\
\hline
\end{tabular}

Table 4. Normalized decision matrix $p_{i j}$

\begin{tabular}{|l|c|c|c|c|c|c|}
\hline $\begin{array}{c}\text { Performance } \\
\text { criteria }\end{array}$ & $\begin{array}{c}\text { Quantity of } \\
\text { work }\end{array}$ & Quality of work & Technical skills & Cooperation & Loyalty & Willingness \\
\hline $\begin{array}{c}\text { Optimization } \\
\text { direction }\end{array}$ & $\max$ & $\max$ & $\max$ & $\max$ & $\max$ & $\max$ \\
\hline & $\mathrm{C} 1$ & $\mathrm{C} 2$ & $\mathrm{C} 3$ & $\mathrm{C} 4$ & $\mathrm{C} 5$ & C6 \\
\hline S1 & 0.067088 & 0.067194 & 0.064885 & 0.069767 & 0.070588 & 0.0625 \\
\hline S2 & 0.06472 & 0.063241 & 0.064885 & 0.062016 & 0.062745 & 0.058594 \\
\hline S3 & 0.067877 & 0.059289 & 0.064885 & 0.069767 & 0.058824 & 0.0625 \\
\hline S4 & 0.059195 & 0.071146 & 0.057252 & 0.073643 & 0.062745 & 0.074219 \\
\hline S5 & 0.062352 & 0.067194 & 0.072519 & 0.065891 & 0.066667 & 0.070313 \\
\hline S6 & 0.065509 & 0.071146 & 0.072519 & 0.069767 & 0.066667 & 0.066406 \\
\hline S7 & 0.063141 & 0.067194 & 0.057252 & 0.065891 & 0.070588 & 0.058594 \\
\hline S8 & 0.072612 & 0.071146 & 0.068702 & 0.05814 & 0.066667 & 0.066406 \\
\hline S9 & 0.069455 & 0.067194 & 0.072519 & 0.05814 & 0.066667 & 0.078125 \\
\hline S10 & 0.072612 & 0.067194 & 0.064885 & 0.073643 & 0.062745 & 0.066406 \\
\hline S11 & 0.070245 & 0.071146 & 0.061069 & 0.073643 & 0.066667 & 0.058594 \\
\hline S12 & 0.061563 & 0.059289 & 0.076336 & 0.062016 & 0.070588 & 0.0625 \\
\hline S13 & 0.06472 & 0.063241 & 0.064885 & 0.065891 & 0.066667 & 0.066406 \\
\hline S14 & 0.067877 & 0.059289 & 0.068702 & 0.065891 & 0.07451 & 0.070313 \\
\hline S15 & 0.071034 & 0.075099 & 0.068702 & 0.065891 & 0.066667 & 0.078125 \\
\hline
\end{tabular}

Table 5. Computed $e_{j}$, information entropy of attribute $C_{j}$

\begin{tabular}{|l|c|c|c|c|c|c|}
\hline $\begin{array}{c}\text { Performance } \\
\text { criteria }\end{array}$ & $\begin{array}{c}\text { Quantity of } \\
\text { work }\end{array}$ & Quality of work & Technical skills & Cooperation & Loyalty & Willingness \\
\hline $\begin{array}{c}\text { Optimization } \\
\text { direction }\end{array}$ & $\max$ & $\max$ & $\max$ & $\max$ & $\max$ & $\max$ \\
\hline & $\mathrm{C} 1$ & $\mathrm{C} 2$ & $\mathrm{C} 3$ & $\mathrm{C} 4$ & $\mathrm{C} 5$ & $\mathrm{C} 6$ \\
\hline S1 & -0.06693 & -0.067 & -0.06553 & -0.0686 & -0.0691 & -0.06399 \\
\hline S2 & -0.06543 & -0.06447 & -0.06553 & -0.06367 & -0.06415 & -0.06139 \\
\hline S3 & -0.06743 & -0.06186 & -0.06553 & -0.0686 & -0.06154 & -0.06399 \\
\hline S4 & -0.06179 & -0.06944 & -0.06047 & -0.07094 & -0.06415 & -0.07128 \\
\hline S5 & -0.06389 & -0.067 & -0.07027 & -0.06618 & -0.06667 & -0.06893 \\
\hline S6 & -0.06593 & -0.06944 & -0.07027 & -0.0686 & -0.06667 & -0.0665 \\
\hline S7 & -0.06441 & -0.067 & -0.06047 & -0.06618 & -0.0691 & -0.06139 \\
\hline S8 & -0.07032 & -0.06944 & -0.06794 & -0.06108 & -0.06667 & -0.0665 \\
\hline S9 & -0.0684 & -0.067 & -0.07027 & -0.06108 & -0.06667 & -0.07355 \\
\hline S10 & -0.07032 & -0.067 & -0.06553 & -0.07094 & -0.06415 & -0.0665 \\
\hline S11 & -0.06889 & -0.06944 & -0.06305 & -0.07094 & -0.06667 & -0.06139 \\
\hline
\end{tabular}


Table 5 (cont.). Computed $e_{j}$, information entropy of attribute $C_{j}$

\begin{tabular}{|l|c|c|c|c|c|c|}
\hline $\begin{array}{c}\text { Performance } \\
\text { criteria }\end{array}$ & $\begin{array}{c}\text { Quantity of } \\
\text { work }\end{array}$ & Quality of work & Technical skills & Cooperation & Loyalty & Willingness \\
\hline $\begin{array}{c}\text { Optimization } \\
\text { direction }\end{array}$ & $\max$ & $\max$ & $\max$ & $\max$ & $\max$ & $\max$ \\
\hline & $\mathrm{C} 1$ & $\mathrm{C} 2$ & $\mathrm{C} 3$ & $\mathrm{C} 4$ & $\mathrm{C} 5$ & $\mathrm{C} 6$ \\
\hline $\mathrm{S} 12$ & -0.06337 & -0.06186 & -0.07252 & -0.06367 & -0.0691 & -0.06399 \\
\hline $\mathrm{S} 13$ & -0.06543 & -0.06447 & -0.06553 & -0.06618 & -0.06667 & -0.0665 \\
\hline $\mathrm{S} 14$ & -0.06743 & -0.06186 & -0.06794 & -0.06618 & -0.07145 & -0.06893 \\
\hline $\mathrm{S} 15$ & -0.06937 & -0.0718 & -0.06794 & -0.06618 & -0.06667 & -0.07355 \\
\hline$e_{j}$ & -0.99935 & -0.99905 & -0.99879 & -0.99898 & -0.9994 & -5.99395 \\
\hline
\end{tabular}

The entropy based WSM method handles both beneficial and non-beneficial criteria and employs separate mathematical processes in contrast to other methods. Entropy method is applied to the decision matrix in Table 3, the stepwise computed values are shown through Tables 4-6, and objective criteria weights are obtained as shown in Table 7.

Table 6. Computed $d_{j}$, degree of divergence of attribute $C_{j}$

\begin{tabular}{|c|c|c|c|c|c|c|}
\hline $\begin{array}{c}\text { Performance } \\
\text { criteria }\end{array}$ & $\begin{array}{c}\text { Quantity of } \\
\text { work }\end{array}$ & Quality of work & Technical skills & Cooperation & Loyalty & Willingness \\
\hline $\begin{array}{c}\text { Optimization } \\
\text { direction }\end{array}$ & $\max$ & $\max$ & $\max$ & $\max$ & $\max$ & $\max$ \\
\hline & $\mathrm{C} 1$ & $\mathrm{C} 2$ & $\mathrm{C} 3$ & $\mathrm{C} 4$ & $\mathrm{C} 5$ & $\mathrm{C} 6$ \\
\hline$d_{j}$ & 0.000654 & 0.000947 & 0.001207 & 0.001022 & 0.000597 & 0.001626 \\
\hline
\end{tabular}

Table 7. Computed $\omega_{j}$, criterion weight of attribute $C_{j}$.

\begin{tabular}{|c|c|c|c|c|c|c|}
\hline $\begin{array}{c}\text { Performance } \\
\text { criteria }\end{array}$ & $\begin{array}{c}\text { Quantity of } \\
\text { work }\end{array}$ & Quality of work & Technical skills & Cooperation & Loyalty & Willingness \\
\hline $\begin{array}{c}\text { Optimization } \\
\text { Direction }\end{array}$ & $\max$ & $\max$ & $\max$ & $\max$ & $\max$ & $\max$ \\
\hline & $\mathrm{C} 1$ & $\mathrm{C} 2$ & $\mathrm{C} 3$ & $\mathrm{C} 4$ & $\mathrm{C} 5$ & $\mathrm{C} 6$ \\
\hline$\omega_{j}$ & 0.108049 & 0.156361 & 0.199464 & 0.168807 & 0.098658 & 0.26866 \\
\hline
\end{tabular}

\section{B. The application of the Weighted Sum Method (WSM)}

The decision matrix with optimal values shown in Table 8 is normalized using Eq. (6) as seen in Table 9. All six criteria, quantity of work, quality of work, technical skills, cooperation, loyalty, willingness in decision matrix with optimal values are considered as maximization objectives or benefit criteria as shown in Table 8.The normalized decision matrix with optimal values as shown in Table 9 is considered as the basis for the weighted normalized decision matrix as shown Table 13. Ranking of alternatives and selection of the most acceptable alternative are shown in Table 14.

Table 8. Decision matrix with optimal values

\begin{tabular}{|l|c|c|c|c|c|c|}
\hline $\begin{array}{c}\text { Performance } \\
\text { criteria }\end{array}$ & $\begin{array}{c}\text { Quantity of } \\
\text { work }\end{array}$ & Quality of work & Technical skills & Cooperation & Loyalty & Willingness \\
\hline $\begin{array}{c}\text { Optimization } \\
\text { direction }\end{array}$ & $\max$ & $\max$ & $\max$ & $\max$ & $\max$ & $\max$ \\
\hline & $\mathrm{C} 1$ & $\mathrm{C} 2$ & $\mathrm{C} 3$ & $\mathrm{C} 4$ & $\mathrm{C} 5$ & C6 \\
\hline S0 & $\mathbf{4 6 0}$ & $\mathbf{9 5}$ & $\mathbf{1 0 0}$ & $\mathbf{9 5}$ & $\mathbf{9 5}$ & $\mathbf{1 0 0}$ \\
\hline S1 & 425 & 85 & 85 & 90 & 90 & 80 \\
\hline S2 & 410 & 80 & 85 & 80 & 80 & 75 \\
\hline S3 & 430 & 75 & 85 & 90 & 75 & 80 \\
\hline S4 & 375 & 90 & 75 & 95 & 80 & 95 \\
\hline S5 & 395 & 85 & 95 & 85 & 85 & 90 \\
\hline S6 & 415 & 90 & 95 & 90 & 85 & 85 \\
\hline
\end{tabular}


Table 8 (cont.). Decision matrix with optimal values

\begin{tabular}{|l|c|c|c|c|c|c|}
\hline $\begin{array}{c}\text { Performance } \\
\text { criteria }\end{array}$ & $\begin{array}{c}\text { Quantity of } \\
\text { work }\end{array}$ & Quality of work & Technical skills & Cooperation & Loyalty & Willingness \\
\hline $\begin{array}{c}\text { Optimization } \\
\text { direction }\end{array}$ & $\max$ & $\max$ & $\max$ & $\max$ & $\max$ & $\max$ \\
\hline & $\mathrm{C} 1$ & $\mathrm{C} 2$ & $\mathrm{C} 3$ & $\mathrm{C} 4$ & $\mathrm{C} 5$ & C6 \\
\hline S7 & 400 & 85 & 75 & 85 & 90 & 75 \\
\hline S8 & 460 & 90 & 90 & 75 & 85 & 85 \\
\hline S9 & 440 & 85 & 95 & 75 & 85 & 100 \\
\hline S10 & 460 & 85 & 85 & 95 & 80 & 85 \\
\hline S11 & 445 & 90 & 80 & 95 & 85 & 75 \\
\hline S12 & 390 & 75 & 100 & 80 & 90 & 80 \\
\hline S13 & 410 & 80 & 85 & 85 & 85 & 85 \\
\hline S14 & 430 & 75 & 90 & 85 & 95 & 90 \\
\hline S15 & 450 & 95 & 90 & 85 & 85 & 100 \\
\hline
\end{tabular}

Table 9. Normalized decision matrix with optimal values

\begin{tabular}{|l|c|c|c|c|c|c|}
\hline $\begin{array}{c}\text { Performance } \\
\text { criteria }\end{array}$ & $\begin{array}{c}\text { Quantity of } \\
\text { work }\end{array}$ & Quality of work & Technical skills & Cooperation & Loyalty & Willingness \\
\hline $\begin{array}{c}\text { Optimization } \\
\text { direction }\end{array}$ & $\max$ & $\max$ & $\max$ & $\max$ & $\max$ & $\max$ \\
\hline & $\mathrm{C} 1$ & $\mathrm{C} 2$ & $\mathrm{C} 3$ & $\mathrm{C} 4$ & $\mathrm{C} 5$ & C6 \\
\hline S0 & 0.067696836 & 0.069852941 & 0.070921986 & 0.068592058 & 0.069343066 & 0.072463768 \\
\hline S1 & 0.06254599 & 0.0625 & 0.060283688 & 0.064981949 & 0.065693431 & 0.057971014 \\
\hline S2 & 0.060338484 & 0.058823529 & 0.060283688 & 0.057761733 & 0.058394161 & 0.054347826 \\
\hline S3 & 0.063281825 & 0.055147059 & 0.060283688 & 0.064981949 & 0.054744526 & 0.057971014 \\
\hline S4 & 0.055187638 & 0.066176471 & 0.053191489 & 0.068592058 & 0.058394161 & 0.06884058 \\
\hline S5 & 0.058130979 & 0.0625 & 0.067375887 & 0.061371841 & 0.062043796 & 0.065217391 \\
\hline S6 & 0.061074319 & 0.066176471 & 0.067375887 & 0.064981949 & 0.062043796 & 0.061594203 \\
\hline S7 & 0.058866814 & 0.0625 & 0.053191489 & 0.061371841 & 0.065693431 & 0.054347826 \\
\hline S8 & 0.067696836 & 0.066176471 & 0.063829787 & 0.054151625 & 0.062043796 & 0.061594203 \\
\hline S9 & 0.064753495 & 0.0625 & 0.067375887 & 0.054151625 & 0.062043796 & 0.072463768 \\
\hline S10 & 0.067696836 & 0.0625 & 0.060283688 & 0.068592058 & 0.058394161 & 0.061594203 \\
\hline S11 & 0.06548933 & 0.066176471 & 0.056737589 & 0.068592058 & 0.062043796 & 0.054347826 \\
\hline S12 & 0.057395143 & 0.055147059 & 0.070921986 & 0.057761733 & 0.065693431 & 0.057971014 \\
\hline S13 & 0.060338484 & 0.058823529 & 0.060283688 & 0.061371841 & 0.062043796 & 0.061594203 \\
\hline S14 & 0.063281825 & 0.055147059 & 0.063829787 & 0.061371841 & 0.069343066 & 0.065217391 \\
\hline & 0.066225166 & 0.069852941 & 0.063829787 & 0.061371841 & 0.062043796 & 0.072463768 \\
\hline
\end{tabular}

Table 10. Reference objective method: coordinates of the reference objective equal to the maximal objective values

\begin{tabular}{|l|c|c|c|c|c|c|}
\hline $\begin{array}{l}\text { Performance } \\
\text { criteria }\end{array}$ & $\begin{array}{c}\text { Quantity of } \\
\text { work }\end{array}$ & Quality of work & Technical skills & Cooperation & Loyalty & Willingness \\
\hline $\begin{array}{l}\text { Optimization } \\
\text { direction }\end{array}$ & $\max$ & $\max$ & $\max$ & $\max$ & $\max$ & $\max$ \\
\hline & $\mathrm{C} 1$ & $\mathrm{C} 2$ & $\mathrm{C} 3$ & $\mathrm{C} 4$ & $\mathrm{C} 5$ & $\mathrm{C} 6$ \\
\hline$r_{i}$ & 0.07261247 & 0.075098814 & 0.076335878 & 0.073643411 & 0.074509804 & 0.078125 \\
\hline
\end{tabular}

Objective ranking in multiobjective optimization based reference point (objective) approach is characterized as dependent only on a given set of data, relevant for the decision situation, and independent of any more detailed specification of personal preferences as that given by defining criteria and the partial order in criterion space. The deviations from the reference point $\left(\left|r_{i}-r_{i j}\right|\right)$ are computed as shown in Table 11 and raking 
of alternatives $\left(z_{i}=\min _{j}\left\{\max _{i}\left|r_{i}-r_{i j}\right|\right\}\right)$ is given in Table 12. The best alternative S15 is chosen with the minimum total deviation from the reference points.

Table 11. Reference objective method: deviations from the reference point $\left(\left|r_{i}-r_{i j}\right|\right)$

\begin{tabular}{|l|c|c|c|c|c|c|}
\hline $\begin{array}{l}\text { Performance } \\
\text { criteria }\end{array}$ & $\begin{array}{c}\text { Quantity of } \\
\text { work }\end{array}$ & Quality of work & Technical skills & Cooperation & Loyalty & Willingness \\
\hline $\begin{array}{l}\text { Optimization } \\
\text { direction }\end{array}$ & $\max$ & $\max$ & $\max$ & $\max$ & $\max$ & $\max$ \\
\hline & $\mathrm{C} 1$ & $\mathrm{C} 2$ & $\mathrm{C} 3$ & $\mathrm{C} 4$ & $\mathrm{C} 5$ & C6 \\
\hline S1 & 0.005525 & 0.007905 & 0.01145 & 0.003876 & 0.003922 & 0.015625 \\
\hline S2 & 0.007893 & 0.011858 & 0.01145 & 0.011628 & 0.011765 & 0.019531 \\
\hline S3 & 0.004736 & 0.01581 & 0.01145 & 0.003876 & 0.015686 & 0.015625 \\
\hline S4 & 0.013418 & 0.003953 & 0.019084 & 0 & 0.011765 & 0.003906 \\
\hline S5 & 0.01026 & 0.007905 & 0.003817 & 0.007752 & 0.007843 & 0.007813 \\
\hline S6 & 0.007103 & 0.003953 & 0.003817 & 0.003876 & 0.007843 & 0.011719 \\
\hline S7 & 0.009471 & 0.007905 & 0.019084 & 0.007752 & 0.003922 & 0.019531 \\
\hline S8 & 0 & 0.003953 & 0.007634 & 0.015504 & 0.007843 & 0.011719 \\
\hline S9 & 0.003157 & 0.007905 & 0.003817 & 0.015504 & 0.007843 & 0 \\
\hline S10 & 0 & 0.007905 & 0.01145 & 0 & 0.011765 & 0.011719 \\
\hline S11 & 0.002368 & 0.003953 & 0.015267 & 0 & 0.007843 & 0.019531 \\
\hline S12 & 0.01105 & 0.01581 & 0 & 0.011628 & 0.003922 & 0.015625 \\
\hline S13 & 0.007893 & 0.011858 & 0.01145 & 0.007752 & 0.007843 & 0.011719 \\
\hline S14 & 0.004736 & 0.01581 & 0.007634 & 0.007752 & 0 & 0.007813 \\
\hline S15 & 0.001579 & 0 & 0.007634 & 0.007752 & 0.007843 & 0 \\
\hline
\end{tabular}

Table 12. Reference objective method: raking of alternatives

\begin{tabular}{|l|c|c|}
\hline \multicolumn{1}{|c|}{ Alternatives } & $\max _{i}\left|r_{i}-r_{i j}\right|$ & $z_{i}=\min _{j}\left\{\max _{i}\left|r_{i}-r_{i j}\right|\right\}$ \\
\hline S1 & 0.015625 & $\mathbf{8}$ \\
\hline S2 & 0.019531 & $\mathbf{1 3}$ \\
\hline S3 & 0.01581 & $\mathbf{1 2}$ \\
\hline S4 & 0.019084 & $\mathbf{2}$ \\
\hline S5 & 0.01026 & $\mathbf{3}$ \\
\hline S6 & 0.011719 & $\mathbf{1 4}$ \\
\hline S7 & 0.019531 & $\mathbf{6}$ \\
\hline S8 & 0.015504 & $\mathbf{7}$ \\
\hline S9 & 0.015504 & $\mathbf{4}$ \\
\hline S10 & 0.011765 & $\mathbf{1 5}$ \\
\hline S11 & 0.019531 & $\mathbf{1 0}$ \\
\hline S12 & 0.01581 & $\mathbf{5}$ \\
\hline S13 & 0.011858 & $\mathbf{1 1}$ \\
\hline S14 & 0.01581 & $\mathbf{1}$ \\
\hline S15 & 0.007843 & \\
\hline
\end{tabular}

The normalized decision matrix with optimal values in Table 9 is weighted with objective criteria weights determined by entropy method. The weighted normalized decision matrix with optimal values is shown in Table 13. 
Table 13. Weighted normalized decision matrix with optimal values

\begin{tabular}{|l|c|c|c|c|c|c|}
\hline $\begin{array}{c}\text { Performance } \\
\text { criteria }\end{array}$ & $\begin{array}{c}\text { Quantity of } \\
\text { work }\end{array}$ & Quality of work & Technical skills & Cooperation & Loyalty & Willingness \\
\hline $\begin{array}{c}\text { Optimization } \\
\text { direction }\end{array}$ & $\max$ & $\max$ & $\max$ & $\max$ & $\max$ & $\max$ \\
\hline & $\mathrm{C} 1$ & $\mathrm{C} 2$ & $\mathrm{C} 3$ & $\mathrm{C} 4$ & $\mathrm{C} 5$ & $\mathrm{C} 6$ \\
\hline S0 & 0.007314575 & 0.010922276 & 0.014146383 & 0.011578819 & 0.006841248 & 0.019468116 \\
\hline S1 & 0.006758032 & 0.009772563 & 0.012024426 & 0.010969408 & 0.006481182 & 0.015574493 \\
\hline S2 & 0.006519513 & 0.009197706 & 0.012024426 & 0.009750585 & 0.005761051 & 0.014601087 \\
\hline S3 & 0.006837538 & 0.008622849 & 0.012024426 & 0.010969408 & 0.005400985 & 0.015574493 \\
\hline S4 & 0.005962969 & 0.010347419 & 0.010609787 & 0.011578819 & 0.005761051 & 0.01849471 \\
\hline S5 & 0.006280994 & 0.009772563 & 0.013439064 & 0.010359996 & 0.006121117 & 0.017521304 \\
\hline S6 & 0.006599019 & 0.010347419 & 0.013439064 & 0.010969408 & 0.006121117 & 0.016547899 \\
\hline S7 & 0.0063605 & 0.009772563 & 0.010609787 & 0.010359996 & 0.006481182 & 0.014601087 \\
\hline S8 & 0.007314575 & 0.010347419 & 0.012731745 & 0.009141173 & 0.006121117 & 0.016547899 \\
\hline S9 & 0.00699655 & 0.009772563 & 0.013439064 & 0.009141173 & 0.006121117 & 0.019468116 \\
\hline S10 & 0.007314575 & 0.009772563 & 0.012024426 & 0.011578819 & 0.005761051 & 0.016547899 \\
\hline S11 & 0.007076057 & 0.010347419 & 0.011317106 & 0.011578819 & 0.006121117 & 0.014601087 \\
\hline S12 & 0.006201488 & 0.008622849 & 0.014146383 & 0.009750585 & 0.006481182 & 0.015574493 \\
\hline S13 & 0.006519513 & 0.009197706 & 0.012024426 & 0.010359996 & 0.006121117 & 0.016547899 \\
\hline S14 & 0.006837538 & 0.008622849 & 0.012731745 & 0.010359996 & 0.006841248 & 0.017521304 \\
\hline S15 & 0.007155563 & 0.010922276 & 0.012731745 & 0.010359996 & 0.006121117 & 0.019468116 \\
\hline
\end{tabular}

Finally, the overall ranks are obtained using equations $(4-7 ; 11-14)$ and the results are shown in Table 14. Table 14 shows the overall performance and the rankings of 15 alternatives (employees) considered for multiobjective optimization problem. Alternative S15 is the best employee alternative according to entropy based weighted sum method (WSM) and reference objective method.

Table 14. The ranking of the alternatives by the entropy based weighted sum method (WSM)

\begin{tabular}{|l|c|c|c|}
\hline \multicolumn{1}{|c|}{ Alternatives } & $S_{i}=\sum_{j=1}^{n} u_{i j}$ & $Q_{i}=\frac{S_{i}}{S_{0}}$ & Ranking \\
\hline S0 (Optimal) & $\mathbf{0 . 0 7 0 2 7 1 4 1 8}$ & $\mathbf{1}$ & $\mathbf{-}$ \\
\hline S1 & 0.061580103 & 0.876317923 & $\mathbf{1 5}$ \\
\hline S2 & 0.057854367 & 0.823298704 & $\mathbf{1 3}$ \\
\hline S3 & 0.059429699 & 0.845716519 & $\mathbf{7}$ \\
\hline S4 & 0.062754756 & 0.893033871 & $\mathbf{4}$ \\
\hline S5 & 0.063495038 & 0.903568478 & $\mathbf{3}$ \\
\hline S6 & 0.064023925 & 0.911094829 & $\mathbf{1 4}$ \\
\hline S7 & 0.058185116 & 0.828005437 & $\mathbf{2}$ \\
\hline S8 & 0.062203928 & 0.885195288 & $\mathbf{5}$ \\
\hline S9 & 0.064938583 & 0.924110895 & $\mathbf{1 0}$ \\
\hline S10 & 0.062999333 & 0.896514324 & $\mathbf{1 1}$ \\
\hline S11 & 0.061041605 & 0.868654815 & $\mathbf{1 2}$ \\
\hline S12 & 0.06077698 & 0.864889056 & $\mathbf{6}$ \\
\hline S13 & 0.060770656 & 0.86479906 & $\mathbf{1}$ \\
\hline S14 & 0.062914681 & 0.895309683 & \\
\hline S15 & 0.066758812 & 0.950013741 & \\
\hline
\end{tabular}

The entropy based weighted sum method is, objectively, considered for the multiobjective optimization decision making for online performance tracking. The performance values of the employees, are evaluated by determining the optimal values for the online performance tracking using the objective entropy based weighted sum method in multicriteria decision making analysis. The applied entropy based weighted sum method and reference objective method demonstrate the ability to solve the online performance tracking 
problem in multicriteria decision making analysis. Objective ranking in multiobjective optimization can be based on reference objective approach, because reference levels needed in this approach can be established objectively statistically from the given data set. The objective ranking can be very useful in many operational and strategic management situations.

\section{Conclusions}

In this paper, multiobjective decision making problem for online performance tracking and employee selection is handled and solved by the entropy-based weighting for multiobjective optimization. Online performance tracking multicriteria decision making $(\mathrm{MCDM})$ problem mainly involves a set of feasible alternatives that are evaluated by multiple and conflicting evaluation criteria that vary in importance to the decision maker.

However, often in complex decision making problems the decision maker may be unable or unwilling to provide cohesive and exact numerical judgments regarding the relative importance or weights of criteria. Information entropy is a measure of the degree of disorder within a system. It can quantify the amount of expected and useful information content within criteria values, and it measures the contrast intensity among a set of performance criteria.

The purpose of multiobjective optimization methods is to offer support and ways to find the best compromise solution. A multiobjective problem is generally solved by reducing it to a scalar optimization problem, and, scalarization is the converting of the problem, by aggregation of the components of the objective functions, into a single or a family of single objective optimization problems with a real-valued objective function.

The entropy based weighted sum method (WSM) is proposed to generate the optimal solutions for multiobjective optimization problems. The procedure of the WSM method produces the overall performance of alternatives with respect to various criteria. The result of the method suggests that the S15 employee alternative is the best alternative in the alternatives set. The necessary time for making the final selection is moderate. There is no limit on the number of the criteria and alternatives of the multiobjective problems. Extra parameters do not significantly affect the computational procedure. If any criteria are missing in an alternative, this alternative should be withdrawn from the decision process or given an extremely low symbolic value to the missing criterion.

The WSM method holds some advantages of the other multiobjective decision making methods. The applied computational model is an understandable, comprehensive and balanced approach that provides insights into the prioritization criteria under the employee performance evaluation target value / optimal function value level. The model emphasizes the relative importance of each alternative to the optimal level. Implementation of the model may have significant positive impacts and consequences on future performance implementations by focusing on the most critical areas to gain competitive advantage in the information technology sector.

The multicriteria optimization analysis approach is seen as appropriate model for ranking or selecting the best alternative from a set of alternatives because of satisfactory results obtained from evaluation of online performance tracking. The online performance tracking system is used for the evaluation of employees on the work and supplying a timely ordered sequence of feedback to the organization management for administrative and organizational goals. Multicriteria decision making is based on science to elicit managerial decisions and conduct decision processes in organized systems.

Finally, the evaluation results show that the multicriteria optimization analysis method used to evaluate the employees' performance abilities has scientific reference quality and applicability by solving the multicriteria decision making problem with its strong information technology ability.

\section{References}

1. DeNisi, A. S., Pritchard, R. D. (2006). Performance appraisal, performance management and improving individual performance: a motivational framework. Management and Organization Review, 2(2), 253-277.

2. Murphy, K. R., Cleveland, J. N. (1991). Performance Appraisal: An Organizational Perspective. Allyn and Bacon, Boston.

3. Yu, P.L. (1985). Multiple-criteria Decision Making: Concepts, Techniques, and Extensions. Plenum Publishing Corporation, New York. 
4. Hwang, C. L., Yoon, K. (1981). Multiple Attribute Decision Making Methods and Applications. Springer, Berlin Heidelberg.

5. Triantaphyllou, E. (2000). Multi-criteria Decision Making Methods: A Comparative Study. Kluwer Academic Publishers, Dordrecht.

6. Zadeh, L. A. (1965) Fuzzy sets. Information and Control, 8 (3) 338-353.

7. Wang, H. F. (2000). Fuzzy Multicriteria Decision Making - an Overview, J. Intel. Fuzzy Syst., 9, 61-83.

8. Chen, S. J., Hwang, C. L. (1991). Fuzzy Multiple Attribute Decision Making. Springer Verlag, Berlin.

9. Ribeiro, R. A. (1996). Fuzzy multiple attribute decision making: a review and new preference elicitation techniques, Fuzzy Sets Syst. 78, 155-181.

10. Kall, P., Wallace, S.W. (1994). Stochastic Programming. Wiley, Chichester.

11. Sengupta, J. K. (1981). Optimal Decision under Uncertainty. Springer, New York.

12. Vajda, S. (1972). Probabilistic Programming. Academic Press, New York.

13. Liu, X. (2004). On the methods of decision making under uncertainty with probability information. Int. J. Intel. Syst., 19, 1217-1238.

14. Saaty, T. L. (1980). The Analytic Hierarchy Process. McGraw-Hill, New York.

15. Saaty, T. L. (1983). Priority Setting in Complex Problems. IEEE Transactions on Engineering Management, 30(3), 140-155.

16. Zanakis, S. H., Solomon, A., Wisharta, N., Dublish, S. (1998) Multi-attribute decision making: A simulation comparison of select methods. European Journal of Operational Research, 107(3), 507-529.

17. Oraee, K., Bakhtavar, E. (2010). Selection of Tunnel Support System by Using Multi Criteria DecisionMaking Tools, 29th International Conference on Ground Control in Mining.

18. Abo-Sinna, M. A., Amer, A. H. (2005). Extensions of TOPSIS for multi-objective large-scale nonlinear programming problems. Applied Mathematics and Computation, 162, 243-256.

19. Jahanshahloo, G. R., Lotfi, F. H., Izadikhah, M. (2005). An algorithmic method to extend TOPSIS for decision-making problems with interval data. Applied Mathematics and Computation, 175(2), 1375-1384.

20. Zitzler, E. and Thiele, L. (1999). Multiobjective Evolutionary Algorithms. In IEEE Transactions on Evolutionary Computation, 3(4), November.

21. Zadeh, L. (1963). Optimality and non-scalar-valued performance criteria. In IEEE transactions on Automatic Control.

22. Helff, F., Gruenwald, L., d'Orazio, L. (2016). Weighted Sum Model for Multi-Objective Query Optimization for Mobile-Cloud Database Environments, in the Workshop Proceedings of the EDBT/ICDT 2016 Joint Conference (March 15, 2016, Bordeaux, France) on CEUR-WS.org (ISSN 1613-0073).

23. Triantaphyllou, E., Mann, S. H. (1989). An Examination of the Effectiveness of Multi-Dimensional Decision-Making Methods: A Decision-Making Paradox. International Journal of Decision Support Systems, 5, 303-312.

24. Mendoza, G. A., Martins, H. (2006). Multi-criteria decision analysis in natural resource management: A critical review of methods and new modelling paradigms. Forest Ecology and Management, 230, 1-22.

25. Malczewski, J. (1999). GIS and Multi-Criteria Decision Analysis. John Wiley \& Sons, Inc., New York.

26. Shannon, C. (1948). A Mathematical Theory of Communication. Bell System Technical Journal, 27, 379-423.

27. Xiaoxing, L., Krishnan, A., Mondry, A. (2005). An Entropy-based gene selection method for cancer classification using microarray data. BMC Bioinformatics, 6(76), 1-14.

28. Fishburn, P. C. (1967). Additive Utilities with Incomplete Product Set: Applications to Priorities and Assignments. Operations Research Society of America (ORSA), Baltimore, MD, U.S.A.

29. Karlin, S., Studden, W. J. (1966). Tchebycheff Systems: with Applications in Analysis and Statistics. New York, Interscience Publishers.

30. Ignizio, J. P. (1978). A review of goal programming: a tool for multiobjective analysis. J. Opl. Res. Soc., 29(11), 1109-1119.

31. Zeleny, M. (1974). Linear multiobjective programming. Springer-Verlag, Heidelberg, Berlin, New York. 